\title{
O BRINCAR COMO FERRAMENTA AO DESENVOLVIMENTO SOCIAL NA ESCOLA
}

Viviane Barrozo Manfré, Michele da Silva Carlos, Andreia Cristiane Silva Wiezzel.

Universidade Estadual Paulista - UNESP, Curso de Pedagogia do Departamento de Educação, Presidente Prudente, SP. E-mail: vivianemanfre12@gmail.com. PIBIC/CNPq

\section{RESUMO}

A pesquisa em questão enfoca tema recorrente no que se refere à socialização na educação infantil: a agressividade. Tendo em vista que as crianças ao se depararem com a experiência escolar podem passar por conflitos e tensões diversas, constituindo a agressividade não raras vezes expressões decorrentes, busca-se investigar o impacto de atividades lúdicas aos estados emocionais de uma criança com a intenção de contribuir às suas relações sociais. A pesquisa é realizada com base nos pressupostos da pesquisa qualitativa, do tipo estudo de caso, tendo como referencial as teorias de Aberastury, Moyles e Winnicott. Análises preliminares indicam que a criança investigada, inicialmente, utilizou as atividades lúdicas para dar vazão à agressividade, expressar sentimentos e mostrar sua necessidade de proteção/apoio para enfrentar algumas dificuldades. No momento atual tem utilizado o brincar como enfrentamento a essas dificuldades com o suporte da pesquisadora.

PALAVRAS-CHAVE: Brincar. Desenvolvimento Emocional. Escola.

\section{PLAYING AS A TOOL TO SOCIAL DEVELOPMENT IN SCHOOL}




\section{INTRODUÇÃO}

Dentre os diversos aspectos inerentes ao processo de ensino e aprendizagem na educação infantil, destacamos neste trabalho a questão das relações interpessoais em sala de aula. Sobretudo na educação infantil, em que a criança teoricamente sai do núcleo familiar primário e passa a se relacionar com o grupo escolar, é comum e característico do momento passar por dificuldades de relacionamento em sala de aula, tais como a inibição e a agressividade.

A agressividade, particularmente, tem aparecido de maneira surpreendente no contexto da educação infantil no Brasil e no mundo. Compreender tal fenômeno não é simples, porém, é necessário para que os professores possam atuar de forma a contribuir à melhoria das relações em sala de aula, o que virá a refletir no desempenho escolar e desenvolvimento social das crianças.

Não obstante a agressividade tenha raízes diversas, muitas vezes constituindo resultado de vários fatores (WINNICOTT, 2005), é fato que a criança, ao viver a experiência escolar - assim como já mencionado - passa por situações novas, não corriqueiras, podendo ser a agressividade expressão desse novo momento, uma forma de agir diante de situações conflituosas com as outras crianças ou mesmo com o professor.

A agressividade não é concebida como algo ruim, uma vez que constitui força necessária aos processos adaptativos do ser humano. Para Winnicott $(1982,2005)$ a agressividade faz parte da essência humana, sendo importante no desenvolvimento quando convertida em fonte de energia para realizar trabalhos como a arte, a brincadeira, o estudo etc. A agressividade é prejudicial apenas quando não bem é administrada pelo indivíduo ao longo de seu desenvolvimento emocional. Conforme Winnicott (2005) a agressividade, na maior parte das vezes, está relacionada a aspectos emocionais, o que leva as crianças a manifesta-la no ambiente escolar como forma de auxílio, de pedido de ajuda no controle de suas emoções.

Muitos professores, apesar de considerarem a interferência dos aspectos emocionais em sala aula, se restringem à especulações em torno da determinação das origens da agressividade como forma velada de desresponsabilização. O fato é que a escola precisa representar um ambiente em que à criança seja possível o desenvolvimento integral, incluindo, portanto, as questões que envolvem as relações interpessoais.

Como o desenvolvimento social perpassa diretamente o desenvolvimento emocional, o brincar - atividade que permeia grande parte da vida das crianças da educação infantil - se apresenta, em decorrência de várias funções que pode assumir (MOYLES, 2002), como uma possibilidade de trabalho com as emoções. Para Aberastury (1992) o não brincar pode levar a transtornos emocionais ou ser o resultado destes, podendo alterar o desenvolvimento emocional da criança. Por isso é importante que o professor conheça a importância do brincar ao desenvolvimento emocional, de forma a incluir o brincar na rotina escolar.

Segundo Winnicott (1982) o brincar é fundamental para a criança visto que ele pode possuir significados diferentes e ser utilizado com objetivos diversos por ela, isto é, de acordo com suas necessidades de desenvolvimento. Ao considerarmos o aspecto emocional o brincar aparece como forma de comunicação de sentimentos - algo muito difícil à criança conseguir fazer verbalmente nesse momento do desenvolvimento - e resolução de questões importantes à socialização da criança, em um espaço intermediário entre a realidade e a fantasia. Winnicott (1982) conclui: "a brincadeira fornece uma organização para a iniciação de relações emocionais e assim propicia o desenvolvimento de contatos sociais." (WINICOTT, 1982, p. 163).

É importante, neste contexto, que o adulto oportunize condições para que a brincadeira se desenvolva sem julgamentos e sem interrupções. Para que os benefícios do brincar se façam presentes, a criança precisa se sentir livre para empregar o brincar da forma que necessita em dado momento.

Ao brincar, a criança desloca para o exterior seus medos, angústias e problemas internos, dominando-os por meio da ação. Repete no brinquedo 
todas as situações excessivas para seu ego fraco e isto lhe permite, devido ao domínio sobre os objetos externos a seu alcance, tornar ativo aquilo que sofreu passivamente, modificar um final que Ihe foi penoso, tolerar papéis e situações que seriam proibidas na vida real tanto interna como externamente e também repetir à vontade situações prazerosas. (ABERASTURY, 1992, p.15).

Considerando as contribuições do brincar ao desenvolvimento emocional e social, a pesquisa tem por objetivo realizar intervenção com uma criança da educação infantil que apresenta manifestações agressivas intensas, investigando a influência do brincar sobre os estados emocionais que alimentam a agressividade infantil quando esta foge aos padrões comuns à faixa etária.

\section{METODOLOGIA/DESENVOLVIMENTO}

Este trabalho apresenta resultados parciais de pesquisa qualitativa de tipo estudo de caso. Como instrumentos de coleta de dados foram utilizadas observações, entrevistas com a mãe e professora e atividades lúdicas com a criança participante. A pesquisa foi iniciada no segundo semestre de 2016, em uma Escola Municipal de Educação Infantil do interior de São Paulo, que atende crianças em período integral. O projeto foi aprovado pelo Comitê de Ética em Pesquisa da FCT - Unesp (Processo no 045860/2014).

A criança participante é do sexo masculino e tem quatro anos de idade. Foi encaminhada a participar da pesquisa pela professora, que relatou manifestações excessivas de agressividade "com e sem motivos", o que dificultava muito os relacionamentos em sala por envolver gritos e diversos tipos de ataques físicos e verbais na maior parte do tempo.

A primeira etapa do projeto consistiu na realização de uma reunião com a professora e mãe do aluno envolvido. Nesta reunião, coordenada pelas gestoras da escola, a orientadora da pesquisa apresentou a proposta à mãe, que aceitou prontamente a participação da criança. Na ocasião a pesquisadora colheu a assinatura no Termo de Consentimento Livre e Esclarecido e realizou a entrevista com a mãe, com questões semiestruturadas, com intenção de conhecer melhor a criança, seus antecedentes na escola, características de suas relações familiares e com a escola.

Após a entrevista a pesquisadora realizou observações da criança em sala de aula e durante o intervalo, coletando dados sobre sua forma de se relacionar com as demais crianças da classe e com a professora. Posteriormente fez a entrevista com a professora no Horário de Trabalho Pedagógico Coletivo.

Os encontros são realizados individualmente, uma vez por semana, e duram em torno de cinquenta minutos. Eles ocorrem na própria unidade escolar, durante o período de aula, sendo realizado na biblioteca escolar - espaço revitalizado pelos alunos do Curso de Pedagogia da Unesp. Desta forma, não raro, a criança participante da pesquisa se interessa, também, pela literatura infantil.

O brincar foi escolhido como forma de intervenção porque a brincadeira é a maneira que as crianças encontram para comunicar seus sentimentos agressivos, conflitos, medos, sem que haja retorno do meio. Ao brincar a criança lida de modo criativo com a realidade externa, elaborando situações que lhes foram traumatizantes ou prazerosas. De acordo com Winnicott (1975) a área em que acontece a brincadeira para a criança está entre a realidade psíquica e o mundo externo; ela traz à brincadeira objetos que são de sua realidade externa, usando-os a serviço de algo que deriva da realidade interna ou pessoal. No brincar ela manipula fenômenos externos a serviço de suas fantasias e a estes fenômenos escolhidos atribui significado e sentimentos.

A pesquisadora disponibiliza durante os encontros lúdicos na biblioteca duas caixas, que contém diversos brinquedos comuns, selecionados de acordo com a faixa etária da criança 
(ABERSTURY, 1982). Os brinquedos são levados à escola como em um sistema de brinquedoteca itinerante. A criança tem autonomia para escolher qual brincadeira quer desenvolver bem como os brinquedos que utilizará.

Trabalha-se, na pesquisa, com o brincar espontâneo e neste contexto a pesquisadora apresenta um olhar atento aos brinquedos que a criança escolhe e às brincadeiras que realiza, sensibilizando-se aos sentimentos e dificuldades relacionais manifestados nesses momentos:

Por meio da atividade lúdica a criança expressa seus conflitos e, deste modo, podemos reconstruir o seu passado, assim como no adulto fazemolo através das palavras. Esta é uma prova convincente de que o brinquedo é uma forma de expressar os conflitos passados e presentes. (ABERASTURY, 1992, p. 17)

Em suma, no brincar, a criança teatraliza suas experiências e impressões sendo possível conhecer um pouco sobre ela e trabalhar de forma a auxiliá-la. Os dados coletados são cotejados e analisados de acordo com a técnica de análise de conteúdo e as referências teóricas utilizadas na pesquisa.

\section{RESULTADOS}

A seguir será apresentado o caso de uma criança que aqui chamaremos de João (nome fictício). Os dados são parciais, uma vez que os encontros lúdicos estão em andamento.

No primeiro encontro a criança foi logo pegando os brinquedos, não se mostrou receosa em abrir as caixas, parece que teve sua curiosidade despertada. Era bastante comunicativa e convidou a pesquisadora a participar das brincadeiras. De início explorou todos os brinquedos de uma vez, com muita pressa, assim como agia em sala de aula.

No segundo encontro percebeu a existência da imagem de um lobo - remetendo à história de Chapeuzinho Vermelho - na parede da biblioteca, demonstrando certo incômodo. Um tempo depois pegou o serrote de plástico e começou a "serrar os pés do lobo", sendo essa a brincadeira preferida do encontro, na qual foi possível dar bastante vazão à agressividade.

No encontro seguinte já chegou à biblioteca procurando pela imagem do lobo. Se escondia atrás da "casinha dos três porquinhos" (casinha de fantoches) para tentar atirar brinquedos no lobo. Na sequência pegou o serrote de plástico e "serrou" a cabeça da pesquisadora, sem verbalizações.

João brincou, também, com "instrumentos de médico", ouvindo os batimentos cardíacos da pesquisadora e dando injeção nela; brincou com o quebra-cabeça, de colorir desenhos e com os animais de borracha que estão presentes nas caixas, simulando "lutinhas".

Além disso, o garoto explorou diversos livros que estão presentes na prateleira da sala, mas não solicita a contação da história. João tem se interessado também por consertar com o martelo uma ponte (construída com peças do quebra-cabeça) e de mobiliar uma grande casinha de madeira que se encontra na biblioteca. Depois que a casinha está "arrumada" ele literalmente introduz a cabeça dentro dela e diz que irá dormir/descansar porque tem trabalhado muito consertando a ponte.

João, em um dos encontros lúdicos, pegou um brinquedo que simboliza uma onça e disse que se tratava de sua mãe. Ele seria o tigre e afirmou que ambos iriam "pegar" os outros animais. Na sequência começou a representar atos hostis da onça contra uma girafa, pegou o boi (que representava a si próprio) e disse que ele havia matado a onça.

\section{DISCUSSÃO}

Com base nas análises realizadas verificou-se, até o momento, que, quando a criança se escondia atrás da "casinha dos três porquinhos" esperava que a pesquisadora o protegesse ou 
oferecesse um suporte, para que ele pudesse enfrentar o lobo. A figura o fazia sentir medo e frequentemente solicitava à pesquisadora que se escondesse com ele atrás da casinha e, antes que atacasse o lobo, ficava sob proteção da primeira. João demonstrava querer enfrentar a dificuldade e tinha iniciativa para isto, porém, precisava de um apoio, o que foi oferecido prontamente a ele.

A pesquisadora observa que quando o garoto manuseia os livros ele não o faz com a intenção de que lhe sejam contadas histórias mas com a intenção de contar sua própria história. Utiliza os livros como instrumento para ter a oportunidade de falar sobre sua vida, as coisas de que gosta, as que desagradam. Nesse momento está sendo analisado se essas histórias contadas pelo garoto vão ao encontro de seus medos, receios ou aspectos fantasiosos, algo muito próprio à idade. A tendência é a de que as histórias mostrem a presença de tensões internas, as quais se expressam por meio da imagem do lobo, solicitando ajuda da estagiária por intermédio do brincar.

Percebe-se que a criança mostra, de forma simbólica, um cansaço após enfrentar o lobo. Ao deitar com a cabeça na casinha a criança busca o colo de alguém, busca descansar, protegida de suas tensões. Realiza a fantasia de ter uma casa organizada, silenciosa, na qual seja possível o descanso.

Em geral nas escolas de educação infantil, a partir dos 4 anos, o horário do sono desaparece da rotina. Dessa forma é bem possível que a criança sinta essa diferença, além disso, é comum que a existência de irmãos menores traga um pouco de incômodo ao sono das crianças maiores e essa falta de sono afeta o humor das crianças. As lutas que trava com as outras crianças na escola o deixa desgastado.

Todas as vezes em que faltam alguns minutos para finalizar as atividades lúdicas, a pesquisadora solicita à criança que guarde os brinquedos nas caixas. Todavia, até o momento, a criança não tem atendido tal pedido e, assim que ela começa a guardar os brinquedos a criança começa a retirá-los da caixa. Quando o garoto retira os brinquedos da caixa novamente está querendo demonstrar o desejo de não interromper a brincadeira.

Em relação a essa situação a pesquisadora tem reiterado ao garoto de que na próxima semana, no mesmo dia e horário, eles retornarão àquele mesmo local para continuar a brincar, ao que o garoto não parece confiar muito. Nesta perspectiva estamos trabalhando com a confiança e a pesquisadora se disporá a ajudá-lo a guardar os brinquedos.

Em sala de aula, da mesma forma, será orientando ao garoto que antes de "bater" em algum colega por algum motivo, ele precisa conversar, seja com o próprio colega ou com a professora, informando sobre a situação, isto é, tentar resolver a questão sem puxar os cabelos de ninguém ou dar chutes. Da mesma forma será orientada a professora a observar e a mediar essas situações, conversando com as crianças e auxiliando-as na percepção de seus sentimentos, mostrando que há outras formas de resolução desses impasses.

Como a linguagem ainda não está plenamente desenvolvida cabe à escola orientar a criança acerca da importância do diálogo e, a professora, observando algum conflito entre as crianças, trabalhar na mediação, verificando se o garoto não está sendo provocado. Algo frequente e que em nada auxilia as crianças no desenvolvimento da socialização nesta faixa etária é deixar que "elas mesmas se resolvam". As crianças precisam de modelos, ser orientadas sobre formas construtivas de resolução de conflitos para que, posteriormente, cada um a seu tempo, coloque em prática.

\section{CONCLUSÃO}

João tem encontrado nas brincadeiras a possibilidade de trabalhar sentimentos e tensões que esteja passando, repetindo no brincar as situações cotidianas, trabalhando com dados da realidade e, ainda, se divertindo. Portanto, o brincar é uma atividade privilegiada ao desenvolvimento emocional e a criança precisa ter oportunidades e ser estimulada a brincar no lar e na escola. 
Como pode ser observado não é necessário que seja um brincar estruturado, com claros objetivos educacionais, assim como aponta Moyles (2006) ao se referir à prática na escola. Tampouco se refere àquele brincar que os professores autorizam quando as crianças aguardam as demais concluírem as atividades. Refere-se ao brincar espontâneo, em que haja um adulto que as observem, que utilizem esse momento para conhecê-las melhor e refletir formas de trabalharem com elas em sala de aula.

As conclusões finais acerca da investigação da influência dos encontros lúdicos à agressividade em sala de aula constituirá parte da pesquisa ainda em desenvolvimento, porém, temos indícios, por meio de seu brincar, de que a criança já está a caminho de se sentir mais fortalecida, mais segura, tendendo a se responsabilizar gradualmente pela agressividade, amparada por quem cuida de sua formação.

\section{REFERÊNCIAS}

ABERASTURY, Arminda. A criança e seus jogos. 2 ed. Porto Alegre: Artemed, 1992.

MOYLES, J. R. et al. A experiência do brincar: a importância da brincadeira na transição entre a educação infantil e anos iniciais. Trad. Maria Adriana Veríssimo Veronese. Porto Alegre: Artmed, 2006.

WINNICOTT, D. W. A criança e o seu mundo. 6 ed. Rio de Janeiro: LTC - Livros Técnicos e Científicos Editora S.A., 1982.

WINNICOTT, D. W. Privação e delinqüência. 4 ed. São Paulo: Martins Fontes, 2005. 